\title{
COMPETÊNCIAS DIGITAIS E INFORMACIONAIS NO ENSINO SUPERIOR: UM ESTUDO COM ACADÊMICOS NA UNIVERSIDADE FEDERAL DO RIO GRANDE - FURG'
}

\author{
DIGITAL AND INFORMATION LITERACY IN HIGHER EDUCATION: \\ A STUDY WITH STUDENTS IN UNIVERSIDADE FEDERAL DO RIO GRANDE - FURG
}

\author{
Natalia Bermudez Godinho ${ }^{2}$ \\ Renata Braz Gonçalves ${ }^{3}$ \\ Alex Serrano de Almeida ${ }^{4}$
}

\section{RESUMO}

Este trabalho apresenta resultados de pesquisa mais ampla que buscou verificar como ocorrem as buscas informacionais para realização de pesquisas acadêmicas de estudantes universitários dos cursos vinculados ao Instituto de Ciências Humanas e da Informação (ICHI) da Universidade Federal do Rio Grande - FURG, tendo como enfoque a competência informacional. Neste texto focaliza-se a competência digital, elemento importante e considerado inter-relacionado com a competência informacional. O estudo abrangeu uma amostra de 85 estudantes e a metodologia teve uma abordagem quanti-qualitativa. Dentre os respondentes mais jovens, 34 consideraram ter um bom desempenho no uso do computador e 28 no uso da internet, já entre a faixa etária acima de 30 anos, nove consideraram ter um desempenho razoável no uso do computador e 12 julgam ter um bom desempenho na utilização da internet. Uma parcela significativa dos estudantes considera como bom seu acesso à internet. Percebeu-se em alguns investigados sentimentos de exclusão. A maioria dos estudantes acredita que saber utilizar o computador e internet pode influenciar na realização de suas pesquisas. A maioria respondeu ter dificuldade ou desconhecimento no uso de gestores de referência, bases de dados e programas de aplicativos, por outro lado, disseram não ter dificuldade no uso de e-mail, redes sociais e catálogos de bibliotecas. As dificuldades apresentadas pelos estudantes sugerem a necessidade de fomento à competência digital e informacional, trabalhando-se, preferencialmente, esses conceitos integrados.

PALAVRAS-CHAVE: Competência em informação. Tecnologia da informação e comunicação. Ensino superior. Competência digital.

\begin{abstract}
This paper presents results of a more extensive study that sought to evaluate how the informational searches occur in academic research by Instituto de Ciências Humanas e da Informação by Universidade Federal do Rio Grande focusing on the concept of information literacy. This text focuses on the digital literacy, which is considered an important element and is interrelated with the information literacy. The study covered a sample of 85 students and the methodology had a quantitative and qualitative approach. Among the youngers who answered the questionnaire, 34 consider they have good performance using a computer and 28 using the internet, between the age group above 30 years, nine considered having a reasonable performance in computer

\footnotetext{
${ }^{1}$ Artigo proveniente do projeto de pesquisa intitulado Competência Informacional de Estudantes Universitários: análise nos cursos do ICHI-FURG, com financiamento de bolsa de iniciação científica PROBIC-FURG.

2 Bacharela em Biblioteconomia pela Universidade Federal do Rio Grande - FURG. E-mail: nataliabgodinho@gmail.com

${ }^{3}$ Professora do Curso de Biblioteconomia do Instituto de Ciências Humanas e da Informação / Universidade Federal do Rio Grande - FURG. Bacharel em Biblioteconomia (FURG) Mestre e Doutora em Educação (UFPel). E-mail: renatas.braz@gmail.com

${ }^{4}$ Bacharel em Biblioteconomia pela Universidade Federal de Rio Grande (FURG). Especialista em Docência no Ensino Superior (UNICESUMAR). Atualmente, Bibliotecário-Documentalista da Universidade Federal de Santa Maria (UFSM). E-mail: alex.almeida@ufsm.br
}

Recebido em: 16/06/2014 - Aceito em: 14/04/2015
\end{abstract}


use and 12 believe they have a good performance using the internet. A significant portion of the students considers yourself good accessing the internet. It was noticed exclusion feelings in some students investigated. Most students believe that knowing how to use the computer and internet will influence in their research. Most reported having difficulty or ignorance in the use of reference managers, databases, and application programs, however, they said had no difficulty in using e- mail, social networking and library catalogs. The difficulties presented by the students suggest the need for promotion of digital and information literacy, preferably by working with the integration of these concepts.

KEYWORDS: Information literacy. Information and communication technology. Higher education. Digital literacy.

\section{INTRODUÇÃO}

O processo de ensino-aprendizagem dentro da universidade recebe apoio de tecnologias digitais que facilitam a disseminação das informações e aumentam a velocidade comunicacional entre os indivíduos. O computador transformou-se em uma ferramenta essencial para os estudantes realizarem suas tarefas, para localizarem informações acadêmicas, realizarem rematrículas, encaminharem trabalhos aos docentes, inscreverem-se em eventos, acessarem ambientes virtuais de aprendizagem (como a plataforma Moodle, por exemplo).

As Tecnologias de Informação e Comunicação (TIC) compreendem uma variada gama de recursos tecnológicos, que propiciam melhor desenvolvimento do processo de ensino-aprendizagem, assim, no entendimento de Masetto (2011, p. 612-613), elas envolvem o

[...] uso da informática, do computador, da internet, do CD Rom, da hipermídia, da multimídia, de ferramentas para a educação à distância como chat, grupos ou lista de discussão, correio eletrônico, etc. e de outros recursos e linguagens digitais de que atualmente dispomos e que podem colaborar significativamente para tornar o processo de educação mais eficiente e mais eficaz.

Assim, faz-se necessário que os estudantes sejam competentes no uso das TIC para atenderem as demandas acadêmicas, isto é, sejam alfabetizados digitalmente. Contudo, também é relevante que além de serem fluentes no uso desses recursos, tornem-se aptos a lidar com as informações mediadas por essas tecnologias, ou seja, desenvolvam competência informacional.

No âmbito espanhol, a Comisión Sectorial de Tecnologías de la Información y las Comunicaciones de la Conferencia de Rectores de las Universidades Españolas (CRUE-TIC) e a Comisión Sectorial de la Red de Bibliotecas Universitarias (REBIUN) desenvolveram um documento buscando a integração entre a competência digital e a informacional no ensino superior. Desse modo, para essas entidades, a competência digital se relaciona ao uso das TIC, e pode ser compreendida como

[...] o conjunto de conhecimentos, habilidades, atitudes e condutas que capacitam os indivíduos para saber como funcionam as TIC, para que servem e como podem ser 
utilizadas para conseguir objetivos específicos (CRUE-TIC; REBIUN, 2012, p. 6, tradução nossa).

Por outro lado, a competência em informaçãoestá relacionada aos diversos estágios que permeiam o processo de busca, avaliação e uso da informação na resolução de problemas, conforme apontado pela CRUE-TIC e REBIUN (2012, p. 6, tradução nossa), ou seja, trata-se do,

[...] conjunto de conhecimentos, habilidades, atitudes e condutas que capacitam os indivíduos para reconhecer quando necessitam informação, onde localizá-la, como avaliar sua idoneidade e utilizá-la de forma adequada de acordo com o problema que se apresentar.

Uma atividade relevante no contexto educacional universitário é a elaboração de pesquisas científicas que possibilitam aos estudantes investigarem determinados fenômenos contribuindo para a construção de seu próprio conhecimento.

Os acadêmicos, para a realização de suas pesquisas podem se beneficiar do uso de TIC, pois essas tecnologias agilizam as buscas, permitem a avaliação das fontes de informação através de critérios apontados, por exemplo, pelo WebQualis ${ }^{5}$. Além disso, favorecem a análise da temática de pesquisa desenvolvida por outros pesquisadores ao acessarem os Currículos Lattes $^{6}$ desses, pela possibilidade de criar serviços de alertas ${ }^{7}$ a partir de buscadores, entre outras ferramentas. Essas tecnologias auxiliam na escrita de projetos e relatório de pesquisa a partir do uso de editores de texto, os quais segundo Novaes (2011, p. 98), "[...] trouxeram novos recursos ao ato de redigir, ampliando as possibilidades de produção, sem prejuízo algum do ato de criação."

Desse modo, além dos estudantes serem competentes no uso de TIC, eles devem ser competentes em localizar, avaliar e fazer bom uso das informações encontradas a partir do uso dessas tecnologias.

Gasque (2012, p. 53) aborda a competência em informaçãosob a expressão Letramento Informacional e ressalta que ele "[...] pode ser compreendido como a capacidade de pesquisar e resolver problemas complexos por meio de metodologia científica, considerando o pensar reflexivo." Já Silva (2008, p. 103) ressalta a importância da literacia da informação - Information Literacy - como "[...] um dos mais importantes requisitos de que precisa o estudante universitário da sociedade da informação."

Com isso, o objetivo deste trabalho foi averiguar como estudantes universitários do terceiro ano, vinculados ao Instituto de Ciências Humanas e da Informação (ICHI) da Universidade Federal do Rio Grande - FURG efetuam buscas informacionais para realizar pesquisas acadêmicas. Ademais, buscou-se analisar a inter-relação do conceito de competência digital com a competência informacional, pois se considera que essas

\footnotetext{
${ }^{5}$ WebQualis. Disponível em: <http://qualis.capes.gov.br/webqualis/>. Acesso em 24 set. 2013.

${ }^{6}$ Plataforma Lattes. Disponível em: <http://lattes.cnpq.br/>. Acesso em 24 set. 2013.

${ }^{7}$ Um exemplo seria o Serviço de Alerta do Google Acadêmico.
} 
tecnologias são ferramentas que prestam suporte aos trabalhos universitários e são veículos que favorecem a mediação de informações, auxiliando de maneira substancial, na elaboração de pesquisas e trabalhos acadêmicos.

\section{PROCEDIMENTOS METODOLÓGICOS}

A pesquisa abrangeu uma população de 250 acadêmicos do terceiro ano dos cursos de Bacharelado em Arquivologia, Biblioteconomia, Psicologia, Geografia e Licenciatura em Geografia. A amostra não foi definida a priori sendo determinada a partir da aplicação de um instrumento de coleta, ou seja, foi definida a partir dos estudantes que se encontravam presentes em sala de aula, resultando em um total de 85 alunos. Salienta-se que a coleta foi realizada no primeiro semestre de 2012.

O estudo em pauta define-se em uma abordagem quanti-qualitativa, pois esta pesquisa apresentou características quantitativas, norteado pela mensuração de variáveis (idade, posse de computador, acesso à internet, entre outras), pré-determinadas pelos pesquisadores deste trabalho. Além disso, expôs aspectos qualitativos por meio da subjetividade das inferências realizadas pelos autores em decorrência da análise dos dados e, também, apresentando baixa ou nula possibilidade de generalização (APPOLINÁRIO, 2011, p. 61-62). Ainda, em relação à abordagem qualitativa, buscou-se apoio em Minayo (2010, p. 21), a qual ressalta que a pesquisa qualitativa "[...] trabalha com o universo dos significados, dos motivos, das aspirações, das crenças, dos valores e das atitudes [...]", ou seja, um "[...] conjunto de fenômenos humanos [...]" que fazem "[...] parte da realidade social."

O instrumento de coleta de dados utilizado foi um questionário, sob influência do trabalho de Bandeira (2009) e de Oliveira (2005). Em relação ao questionário devem-se considerar algumas limitações que esse instrumento apresenta, pois ele fornece dados a partir da opinião dos investigados não verificando as habilidades dos investigados na prática, como apontado por Costa (2011, p. 143).

A seguir aborda-se o referencial teórico discutindo a inter-relação entre a competência digital e a competência informacional.

\section{COMPETÊNCIA DIGITAL INTER-RELACIONADA À COMPETÊNCIA EM INFORMAÇÃO}

Pode-se entender o conceito de competência digital a partir das Normas da Association of College and Research Libraries (ACRL), como destrezas que permitem aos indivíduos utilizarem "[...] computadores, aplicações informáticas, bases de dados e outras tecnologias para alcançar uma grande variedade de metas acadêmicas, do trabalho e pessoais.” (ACRL, 2000, p. 2, tradução nossa). Essas normas defendem ainda a interligação entre as TIC e a competência em informaçãoquando ressalta que "Os indivíduos competentes no acesso e uso da informação necessariamente tem que dominar determinadas destrezas 
tecnológicas." (ACRL, 2000, p. 2, tradução nossa).

Além disso, percebe-se a interligação entre as duas competências no contexto universitário no estudo de Hatschbach (2002, p. 95) quando considera a competência em informação como uma área de estudos e práticas que, além da "[...] capacidade de resolução de problemas de informação", faz uso das novas tecnologias.

Bruce (2003) apresenta sete formas ('sete faces') de experienciar a Information Literacy, sendo todas elas importantes na capacitação dos estudantes de modo que eles possam "[...] refletir sobre as variações nas experiências que detectam e entender que formas de alfabetização informacional são relevantes em diferentes situações." (BRUCE, 2003, p. 1, tradução nossa). Em todas essas categorias, as TIC se apresentam ou como foco central (face 1), em um nível médio (face 2), ou com menor enfoque (face 3, 4, 5, 6 e 7).

Da mesma forma, Cavalcante (2006, p. 48) indica a relação entre as competências em informação e o contexto digital, pois,

\begin{abstract}
$\mathrm{Na}$ educação superior [o tema competência informacional] está relacionado principalmente com o uso das tecnologias, em diferentes suportes de informação, para favorecer o desenvolvimento das competências dos estudantes, o que beneficiará o crescimento profissional, a capacidade de realização de pesquisa, planejamento, gestão e avaliação no uso de fontes de informação.
\end{abstract}

Campello (2009, p. 13) abordando a questão da tecnologia da informação e sua vinculação ao letramento informacional ressalta que "Viver na sociedade da informação significa conviver com abundância e diversidade de informação, e a tecnologia é o instrumento que facilita o acesso a esse universo informacional [...]”.

Evidencia-se, conforme exposto, a interligação entre o uso das TIC e a Information Literacy, pois cada vez mais o acesso aos recursos informacionais envolvem o uso dessas tecnologias, com isso, o uso eficaz delas é relevante para a realização de pesquisas pelos estudantes universitários, através do acesso a diferentes canais de comunicação científica, do suporte que as TIC prestam ao processamento de grandes quantidades de dados, entre outros benefícios. Em outras palavras, as TIC podem ser entendidas como um meio ou instrumento que possibilita o acesso, compartilhamento de informações e aprendizagens ${ }^{8}$, os quais contribuem para o desenvolvimento da competência informacional.

Por outro lado, faz-se necessário desenvolver uma postura crítica nos estudantes para que eles analisem com cuidado os benefícios advindos das TIC, principalmente em relação à segurança e confiabilidade das informações. Assim, por exemplo, um estudante competente no uso da informação analisaria se a informação que ele deseja incluir em seu trabalho é apenas uma opinião ou foi fundamentada numa pesquisa que seguiu métodos científicos, recebeu a devida revisão por pares e foi publicada em um periódico científico.

\footnotetext{
${ }^{8}$ Como exemplos de recursos que favoreçam a aprendizagem poder-se-ia citar tutoriais disponíveis no You Tube (http://www.youtube.com/) ou no SlideShare (http://www.slideshare.net/); plataforma Moodle, entre outros.
} 
Além do desenvolvimento de um pensar crítico para avaliar as informações, faz-se necessário que os acadêmicos desenvolvam a capacidade de 'aprender a aprender' o que lhes possibilita adquirir autonomia para continuar sua aprendizagem ao longo da vida. Isso parece tornar-se essencial, principalmente em relação às TIC, pois muitas delas tem se caracterizado pela rápida obsolescência o que requer atualização constante dos indivíduos.

\section{USO DE TIC: RESULTADOS}

Os resultados apresentados a seguir abordam quatro aspectos significativos em relação às TIC: o desempenho dos estudantes, o acesso, sentimentos de exclusão digital e dificuldades encontradas no uso dessas tecnologias.

Considerando a questão 1 do instrumento de coleta ${ }^{9}$, identificou-se inicialmente que 62 estudantes se encontravam na faixa etária ente 15 e 30 anos, 22 acadêmicos entre 31 e 50 anos e apenas 1 (um) apresentou idade entre 51 e 60 anos. Para a construção da Tabela 1, além dessa primeira questão traçou-se uma relação com as questões 7 e 10 e separaram-se os estudantes em dois grupos com faixa etária até 30 anos e acima de 30 anos. Os dados obtidos não visam à comparação entre faixas etárias, muito menos a generalizações devido aos baixos valores amostrais, buscando-se apenas uma descrição do contexto investigado. A escolha pelo valor de 30 anos deu-se em virtude dos intervalos indicados como opção no questionário e também buscou seguir uma faixa etária próxima a utilizada por Neri (2012, p. 77), o qual considerou como os mais jovens, aqueles investigados entre 15 e 29 anos.

TABELA 1- Desempenho no computador e internet por faixa etária

\begin{tabular}{|c|c|c|c|c|}
\hline \multirow[t]{2}{*}{ Desempenho } & \multicolumn{2}{|c|}{$\begin{array}{c}\text { Faixa etária entre } \\
15 \text { e } 30 \text { anos }\end{array}$} & \multicolumn{2}{|c|}{$\begin{array}{c}\text { Faixa etária acima } \\
\text { de } 30 \text { anos }\end{array}$} \\
\hline & Computador & Internet & Computador & Internet \\
\hline Péssimo & - & 2 & 1 & - \\
\hline Ruim & 1 & 3 & 1 & 2 \\
\hline Razoável & 14 & 19 & 9 & 5 \\
\hline Bom & 34 & 28 & 8 & 12 \\
\hline Excelente & 13 & 10 & 4 & 4 \\
\hline Sub-Total & 62 & 62 & 23 & 23 \\
\hline Total & & & & 8 \\
\hline
\end{tabular}

Fonte: dados da pesquisa

A maioria dos estudantes são jovens $(n=62)$ e consideram seu desempenho no computador entre razoável $(n=14)$, bom $(n=34)$ e excelente $(n=13)$, apenas 1 (um) estudante considerou como ruim seu desempenho. Em relação à internet, os investigados consideram seu desempenho como razoável $(n=19)$, bom $(n=28)$ e excelente $(n=10)$ e 5 (cinco) estudantes consideraram-no entre péssimo e ruim.

Entre os respondentes com idade acima de 30 anos, a maioria considera seu desempenho no computador entre razoável $(n=9)$, bom $(n=8)$ e excelente $(n=4)$, apenas 2

${ }^{9} \mathrm{O}$ questionário se encontra no final do artigo. 
(dois) estudantes perceberam seu desempenho entre péssimo e ruim. No que diz respeito à internet, esses acadêmicos consideram seu desempenho como razoável $(n=5)$, bom $(n=12)$ e excelente $(n=4)$ e apenas 2 (dois) pesquisados perceberam-no como ruim.

Outro resultado, obtido a partir da questão cinco, permitiu observar que apenas um acadêmico não possuía computador próprio, sugerindo que, para o maior percentual dos graduandos, se há alguma problemática em relação ao uso das TIC não se configura em falta de equipamento. Não se deve descartar, contudo, a possibilidade de que os indivíduos possuam esse recurso tecnológico, porém não saibam utilizá-lo de forma adequada. Essa hipótese é sugerida a partir do exposto por Danuello e Gonçalves (2011, p. 75): inicialmente a "Exclusão digital referia-se às diversas camadas da sociedade que ficavam literalmente de fora das redes digitais que estavam se formando", ou seja, os indivíduos que não possuíam computadores e internet. Posteriormente, verificou-se que esse problema também se relaciona com a "[...] capacidade de utilizar satisfatoriamente essa tecnologia, o que envolve competências."

No que concerne ao acesso à internet, em relação à velocidade, custos, local, (questão 8) disponível para a elaboração de trabalhos acadêmicos, verificou-se que $25 \%$ dos investigados consideram esse acesso como excelente, $46 \%$ como bom e $21 \%$ como razoável, ver Gráfico 1.

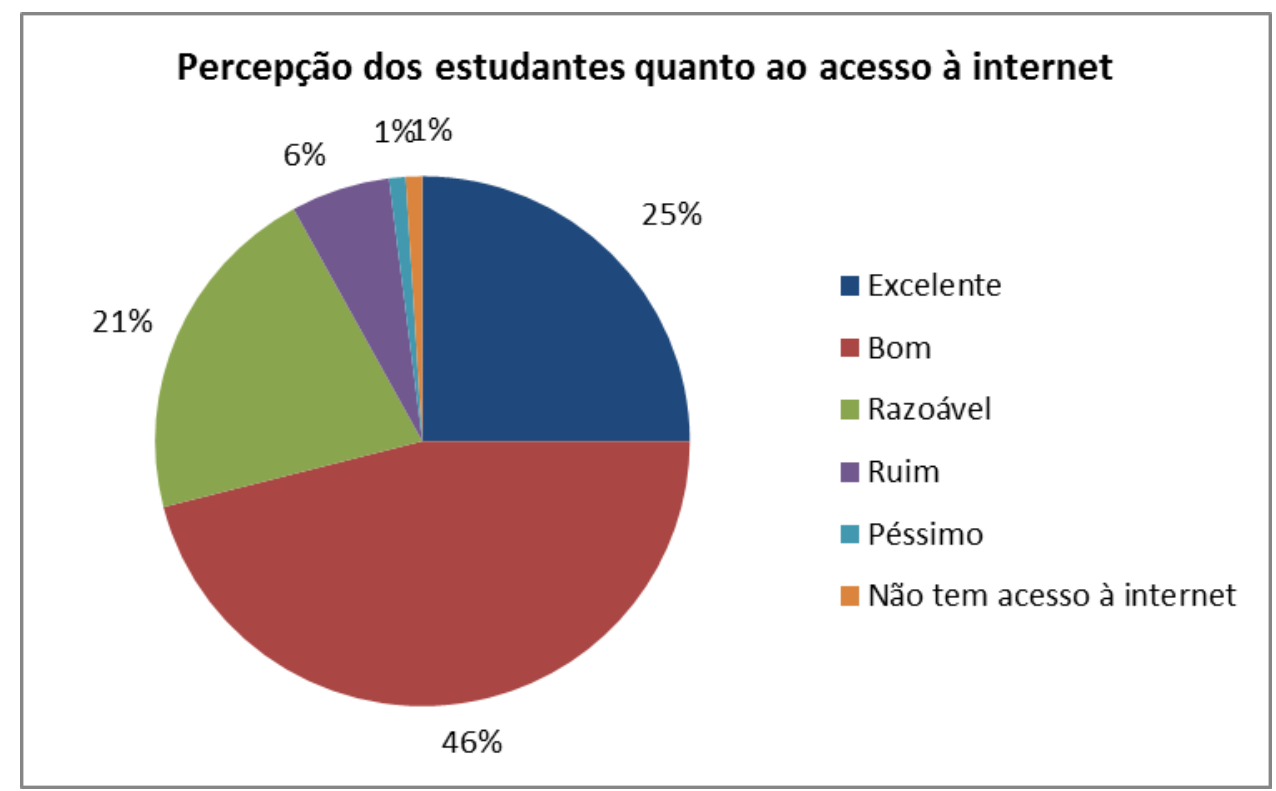

GRÁFICO 1 - Percepção dos estudantes quanto ao acesso à internet (\%)

Fonte: dados da pesquisa

Contudo, para $7 \%$ dos respondentes o acesso é percebido entre péssimo e ruim, e $1 \%$ (que corresponde a um estudante) apontou não ter acesso à internet. Esses dados sugerem que ainda existem estágios a serem atingidos para a concretização da Sociedade da Informação, conceituada pelo Grupo Telefônica no Brasil (2002, p. 16) como aquela sociedade em que seus membros podem "[...] obter e compartilhar qualquer informação, instantaneamente, de qualquer lugar e da maneira mais adequada." Apesar desse acadêmico apontar falta de acesso 
à internet, deve-se ressaltar que a universidade proporciona esse acesso através da biblioteca ou de laboratórios de informática, porém apenas durante a semana, concluindo-se assim, que o acesso do qual o acadêmico apontou deve referir-se àquele disponível em sua residência.

Em relação à questão seis, os resultados indicaram também que a grande maioria dos acadêmicos acredita que o bom desempenho no uso do computador - 81 entre os 85 - pode influenciar na realização de suas pesquisas. Alguns dos investigados opuseram-se a essa afirmativa e apontaram que "Acho que esse bom desempenho pode facilitar mas não é fundamental" (respondente 9h); "Pode ajudar mas não influenciar. Creio que esse aprendizado pode ser adquirido rapidamente" (respondente 1b); "Acredito que não, pois o fato de saber formatar um texto não implica em saber fazer uma pesquisa" (respondente $15 b)$.

De igual modo, em relação à questão nove, a maior parte dos alunos acreditam que o bom desempenho na internet - 79 do total de 85 - pode influenciar na realização de suas pesquisas. Entretanto, outros respondentes discordaram comentando que: "A velocidade pode ajudar a baixar arquivos, mas não influencia na qualidade da utilização destes arquivos" (respondente 28h); "Porque há outras formas de se realizar pesquisas acadêmicas" (respondente 3b); "Pois, não há somente computadores há também livros e periódicos, artigos" (respondente 18b).

Outro dado relevante observado a partir da questão 11 foi que $21 \%$ dos pesquisados, responderam 'sim', que já se sentiram excluídos por não terem domínio ou acesso a ferramentas como computador ou internet. ${ }^{10}$

Percebe-se no discurso de três estudantes, que esses sentimentos de exclusão foram manifestados nos anos iniciais dentro da universidade, "Quando entrei na Universidade, pois tinha pouco conhecimento" (respondente 6b); "No começo, como era novo nesse mundo me sentia meio deslocado" (respondente 15b) ou ainda "No início quando [...] o professor pedia trabalhos digitados e eu não tinha acesso" (respondente 14c).

Nesse contexto, algumas respostas parecem transparecer que o não saber utilizar as ferramentas tecnológicas pode ocasionar sentimentos de exclusão social, como sugerem as seguintes frases: "Porque enquanto todos sabem utilizá-los ou os possuía, eu ficava 'de fora' de tudo" (respondente 3b); "Sim, principalmente por parte dos mais jovens" (respondente 13b); "Pois o não saber te impede de se adequar a certos ambientes" (respondente 17b); "Pois é muito difícil ver todos conseguindo acessar e você não saber" (respondente 15c).

\footnotetext{
${ }^{10}$ Este resultado foi apresentado parcialmente em resumo publicado em anais de evento (referência que segue), porém não conteve os discursos dos investigados, aqui apresentados.

GODINHO, N. B.; GONÇALVES, R. B. Estratégias de pesquisa de estudantes universitários: uma abordagem sob a ótica da competência informacional nos cursos do Instituto de Ciências Humanas e da Informação da Universidade Federal do Rio Grande - FURG. In: CONGRESSO DE INICIAÇÃO CIENTÍFICA, 21., MOSTRA CIENTÍFICA, 4., 2012, Pelotas/RS. Anais...[Pelotas: UFPel], 2012. Disponível em: <http://www2.ufpel.edu.br/cic/2012/anais/sa.htm>. Acesso em: 23 maio 2014.
} 
Ademais, alguns estudantes relacionaram o sentimento de exclusão a não ter acesso ou não ter qualidade no acesso às TIC: "Não ter acesso as ferramentas dificulta a realização de diversas atividades, e o contato com informações e pessoas" (respondente 27h); "Por não ter boa internet em casa, às vezes me sinto perdido nas coisas que tenho que fazer no computador" (respondente 4c). Para outros acadêmicos os sentimentos de exclusão parecem ter se dado em decorrência de não saber utilizar de modo eficiente essas tecnologias o que se percebe nos seguintes discursos: "Senti-me excluída por não saber formatar um trabalho acadêmico" (respondente 7c); "Sim várias vezes por não saber procurar artigos, por exemplo, em fontes confiáveis" (respondente 20c);

Esses sentimentos de exclusão sugerem a necessidade de maiores investigações pautadas em verificar como estão ocorrendo os processos direcionados ao desenvolvimento da competência digital na universidade. Entende-se que o ensino dessas habilidades deve ir além daquele destinado apenas a promover o uso das TIC, pois algumas dessas ferramentas apresentam curto período de vida, caindo na obsolescência. Os indivíduos precisam entender que precisam explorar e conhecer novas ferramentas digitais levados por sua própria motivação, inquietação, de forma autodidata e autônoma, e também que precisam trocar informações sobre TIC com outros colegas, técnicos, professores e bibliotecários.

Nesse sentido, concorda-se com a visão de Takahashi (2000, p. 45, grifo nosso), quando ressalta que educar "[...] em uma sociedade da informação significa muito mais que treinar as pessoas para o uso das tecnologias de informação e comunicação [...]”, essa educação deve buscar que as pessoas 'aprendam a aprender', “[...] de modo a serem capazes de lidar positivamente com a contínua e acelerada transformação da base tecnológica."

Seguindo, a questão 12 buscou verificar a percepção dos estudantes em relação a suas dificuldades em recursos tecnológicos utilizados no âmbito acadêmico para localizar, armazenar, disseminar ou compartilhar informações. Os resultados são apresentados na Tabela 2.

TABELA 2 - Grau de dificuldade em recursos tecnológicos

\begin{tabular}{|c|c|c|c|c|c|}
\hline \multirow[t]{2}{*}{ Recursos tecnológicos } & $\begin{array}{c}\text { Nenhuma } \\
\text { dificulda } \\
\text { de }\end{array}$ & $\begin{array}{c}\text { Alguma } \\
\text { dificulda } \\
\text { de }\end{array}$ & $\begin{array}{c}\text { Muita } \\
\text { dificulda } \\
\text { de/ } \\
\text { não } \\
\text { conhece } \\
\end{array}$ & $\begin{array}{c}\text { Não } \\
\text { respondeu }\end{array}$ & \multirow[t]{2}{*}{ Total } \\
\hline & $\begin{array}{c}\mathrm{n}^{\mathbf{o}} \\
\text { estudantes }\end{array}$ & $\begin{array}{c}\mathrm{n}^{\mathbf{o}} \\
\text { estudantes }\end{array}$ & $\begin{array}{c}\mathrm{n}^{\mathbf{o}} \\
\text { estudantes }\end{array}$ & $\begin{array}{c}\mathrm{n}^{\mathrm{o}} \\
\text { estudantes }\end{array}$ & \\
\hline $\begin{array}{l}\text { Programa de aplicativos } \\
\text { (Excel, PowerPoint ou } \\
\text { similares,...) }\end{array}$ & 36 & 44 & 4 & 1 & 85 \\
\hline $\begin{array}{l}\text { Grupos, listas de } \\
\text { discussões, fóruns } \\
\text { (participar,...) }\end{array}$ & 49 & 29 & 6 & 1 & 85 \\
\hline $\begin{array}{l}\text { Redes sociais (Twitter, } \\
\text { Facebook, Linkedin...) }\end{array}$ & 63 & 19 & 2 & 1 & 85 \\
\hline $\begin{array}{l}\text { E-mail (encaminhar, } \\
\text { anexar arquivos,...) }\end{array}$ & 78 & 5 & 1 & 1 & 85 \\
\hline
\end{tabular}




\begin{tabular}{l}
\hline Bases de dados (Portal de \\
Periódicos da Capes, \\
Scielo,...) \\
\hline Catálogos on-line de bibliotecas (Argo $^{11}$, \\
Biblioteca Nacional,...) \\
\hline Instalação de softwares, \\
aplicativos, ferramentas, \\
navegadores... \\
\hline Ferramentas Web 2.0 \\
(Delicious, GoogleDocs ${ }^{12}$, \\
Google Reader ${ }^{13}$, RSS,...) \\
\hline Gestores de Referências \\
(EndNote, Zotero...) \\
\hline Criação de blogs, páginas $_{\text {na internet }}$ \\
\hline
\end{tabular}

Fonte: dados da pesquisa

Os programas contendo aplicativos voltados à elaboração de planilhas eletrônicas e apresentação de slides são bastante utilizados no meio acadêmico, eles facilitam a tabulação dos dados pesquisados, uso de filtros para melhor análise dos dados, geração de tabelas dinâmicas e gráficos, já a criação de slides busca principalmente auxiliar na apresentação dos trabalhos. A hipótese inicial, a partir das experiências vivenciadas pelos autores, seria de que aplicativos como as planilhas eletrônicas seriam considerados de difícil utilização pelos estudantes, porém somente 4 (quatro) marcaram a opção 'Muita Dificuldade/Não conhece' e 44 estudantes marcaram o item "Alguma dificuldade".

Algumas ferramentas se prestam ao compartilhamento de informações como grupos, listas de discussões, fóruns, entre outras possíveis. Observou-se que 49 estudantes disseram não ter nenhuma dificuldade em utilizá-las, 29 apresentavam alguma dificuldade e 6 (seis) julgavam ter muita dificuldade ou não conheciam esses recursos.

As redes sociais têm sido utilizadas pelo Sistema de Bibliotecas da FURG para divulgar informações acadêmicas e educativas. Em relação ao uso de redes sociais, esse item é apontado por 63 acadêmicos, 29 apresentam 'Alguma dificuldade' e apenas 2 (dois) têm 'Muita dificuldade' ou não as conhecem.

Em outro aspecto, a ferramenta que apresentou maior número de respostas em relação aos estudantes não terem dificuldades no uso foi o e-mail, recurso bastante utilizado para trocas de informações entre acadêmico-acadêmico, e acadêmico- docente, inclusive para o envio de material pedagógico ou de trabalhos dos alunos. Com isso, é essencial que os estudantes saibam lidar com esse recurso, porém, atinente a essas práticas acredita-se que seria mais interessante organizar, armazenar e disponibilizar esses materiais didáticos em plataformas virtuais de aprendizagem, como o Moodle, por exemplo.

\footnotetext{
${ }^{11} \mathrm{O}$ Argo é o catálogo on-line utilizado pelo Sistema de Bibliotecas da FURG.

${ }^{12} \mathrm{O}$ GoogleDocs atualmente se denomina GoogleDrive.

${ }^{13} \mathrm{O}$ Google Reader se encontra encerrado.
} 
As bases de dados, os portais de periódicos eletrônicos e catálogos de bibliotecas disponibilizados on-line são ferramentas relevantes às práticas de pesquisa, a partir dos quais os estudantes acessam artigos de periódicos científicos eletrônicos, teses e dissertações, localizam livros no catálogo da biblioteca, fontes de informação histórica a partir da Biblioteca Nacional, entre outras fontes de informações. Os resultados indicaram que 46 estudantes apresentam alguma dificuldade no uso de bases de dados e 10 marcaram a opção 'Muita dificuldade'. No que tange aos catálogos on-line de bibliotecas 29 consideraram que este item traz alguma dificuldade e apenas 4 (quatro) disseram ter muita dificuldade ou não conhecer esse recurso. Estes dados parecem requerer melhor estudo buscando investigar como está se dando efetivamente a utilização desses recursos pelos acadêmicos, pois muitas vezes as instituições investem consideráveis quantias para oferecer acesso a periódicos científicos ou bases de dados pagas.

Verificou-se que 43 estudantes apontaram o item 'Instalação de softwares, aplicativos, ferramentas, navegadores' como elementos que apresentam 'Alguma dificuldade' e 15 responderam ter 'Muita dificuldade'. Nesse sentido, parece relevante que os estudantes adquiram saberes voltados a instalar anti-vírus, navegadores e outros softwares que poderão os auxiliar na execução de suas tarefas acadêmicas, variando conforme os interesses de cada curso, o que lhes daria maior autonomia ao lidar com as TIC.

Destaca-se que algumas ferramentas para uso na web também podem auxiliar os estudantes em seus trabalhos como o Delicious ${ }^{14}$, alguns aplicativos do Google como o GoogleDrive (antigo GoogleDocs), isso possibilita que estudantes possam, via web elaborar textos ou apresentações em conjunto, criar questionários eletrônicos, entre outros recursos disponibilizados. Ainda nesse item elencavam-se serviços automáticos de disseminação eletrônica de notícias disponibilizadas em sites como o GoogleReader (já encerrado) e o sistema Really Simple Syndication $(R S S)^{15}$. Os resultados mostraram que 22 estudantes não apresentavam dificuldade no uso de ferramentas Web 2.0, mas 37 responderam apresentar alguma dificuldade e 25 muita dificuldade ou não conheciam esses recursos.

Os gestores de referências como o Zotero, Mendeley, EndNote, permitem coletar, organizar, armazenar e recuperar dados bibliográficos e, também os respectivos textos integrais dos documentos, além de se integrarem a editores de texto para gerarem citações e referências. Deste modo, considera-se uma ferramenta bastante útil aos estudantes, principalmente para organizar fontes de informação como artigos científicos, teses e dissertações, entre outras fontes. Nesse contexto, observou-se que 25 acadêmicos apontaram alguma dificuldade e 47 estudantes disseram apresentar muita dificuldade em seu uso ou desconhecerem esse recurso.

O último item da Tabela 2 se referia à criação de blogs ou páginas na internet, recursos esses que podem auxiliar na disseminação de notícias profissionais, acadêmicas ou

${ }^{14}$ Delicious: Ferramenta que permite salvar links de páginas disponíveis na Web ("favoritos") e compartilhá-la com outras pessoas, conhecida como SocialBookmarking. Disponível em: 〈http://delicious.com/>. Acesso em 30 set. 2013.

${ }^{15}$ Conhecido também como Rich Site Summary. 
pessoais, permitindo o acesso a qualquer internauta. Podem ser utilizados pelos docentes para mediar os conteúdos pedagógicos, permitindo a participação dos discentes, através da postagem de trabalhos, comentários ou outras informações. Como resultado observou-se que 28 acadêmicos apontaram alguma dificuldade e 27 responderam muita dificuldade ou não conhecem essas ferramentas.

Os dados coletados nessa questão podem ser úteis no planejamento de atividades universitárias direcionadas ao desenvolvimento da competência digital e informacional, principalmente aqueles indicados na opção 'Muita dificuldade/não conhece' como bases de dados e gestores de referências, devido a sua importância na realização de trabalhos acadêmicos e pesquisas científicas.

Ao final desta análise observa-se que os dados coletados referem-se à percepção dos acadêmicos, porém esta pode não ser adequada às demandas exigidas no contexto acadêmico. Portanto, faz-se necessário em futuras investigações, verificar as habilidades dos graduandos em atividades práticas e realizar entrevistas com os docentes.

\section{CONSIDERAÇÕES FINAIS}

Os estudantes necessitam utilizar as TIC para atender diferentes demandas acadêmicas, para a realização de seus trabalhos, de suas matrículas, consulta ao catálogo online da biblioteca, inscrições em cursos e eventos, acessar plataformas de aprendizagens e localizar na web diferentes fontes de informação. Isso requer que eles possuam competência digital e também informacional, pois se faz necessário além de localizar as informações, saber avaliá-las e utilizá-las adequadamente.

Acredita-se que as dificuldades apresentadas pelos alunos no uso das TIC possam refletir também em sua competência em informaçãodevido à inter-relação entre essas duas competências. Assim, entende-se que ser alfabetizado em TIC e em informação é saber utilizar essas tecnologias de modo eficaz para acessar informações úteis à resolução de um problema. No âmbito universitário elas podem ser utilizadas para fazer a comparação entre um grande número de dados (planilhas eletrônicas), localizar fontes de informação confiáveis (bases de dados, catálogos de bibliotecas), dialogar (e-mail, chat), compartilhar informações (grupos, fóruns, blogs, redes sociais), organizar e recuperar (gestores de referências), comunicar (editores de apresentação) informações acadêmicas.

Desse modo, observou-se nos resultados que alguns estudantes julgam seu desempenho no uso do computador e internet entre ruim e péssimo. Em relação ao acesso às TIC, percebeu-se que a maioria apresenta computador, e, o acesso à internet, para uma pequena parcela dos investigados se configura entre ruim e péssimo. Ainda, a maioria dos respondentes apontou que saber utilizar o computador e a internet pode influenciar na realização de suas pesquisas acadêmicas.

Uma parcela significativa apontou já terem se sentido excluídos, ou devido a problemas relacionados ao acesso às TIC ou por não saberem utilizá-las de modo eficiente. 
Ademais, algumas situações mostram que isso se deu nos anos iniciais da graduação, em outros relatos o analfabetismo digital parece provocar sentimentos ou situações de exclusão social.

Por fim, apresentou-se o grau de dificuldade no uso de diferentes TIC utilizadas no âmbito universitário. Entre as diversas ferramentas investigadas, em que se identificou alguma ou muita dificuldade ou ainda o desconhecimento dessas, podem-se destacar o uso de bases de dados, catálogos on-line e gestores de referências bibliográficas, devido ao grau de importância para a realização de pesquisas científicas.

Os resultados abordaram, desse modo, situações relativas às TIC que se fazem presentes no âmbito universitário e mostram a importância de fomento ao desenvolvimento da competência digital, pois os dados coletados revelaram dificuldades no uso e acesso a essas tecnologias.

Nesse sentido, sugere-se para futuros instrumentos de coleta de dados, o Questionário TIC do PISA 2003 apontado por Waiselfisz (2007, p. 96-97), devidamente adequado ao âmbito que irá ser investigado, apesar de que esse instrumento, assim como o utilizado neste trabalho, parece depender da percepção do respondente, porém torna-se necessário quando a população investigada é numerosa.

Uma opção ao uso do questionário, que poderia ser utilizada em novos estudos, é verificar na prática as habilidades dos estudantes em situações reais de busca de informação, como proposto na tese de Pavão (2014), ou ainda realizar entrevistas com os docentes buscando compreender quais às competências digitais e informacionais necessárias aos discentes para um bom desempenho no âmbito acadêmico.

Tendo em vista o estudo de pesquisadores sobre esta temática e o seu respectivo aprofundamento, sugere-se a análise de programas e projetos ${ }^{16}$ oferecidos pela FURG, que objetivam o fomento das competências aqui discutidas, sua abrangência, sua interseção com os currículos e como ocorre o apoio continuado após o término dos cursos ministrados.

Por fim, sugere-se, como uma opção aos profissionais que desejam implantar programas voltados ao fomento de competências digitais e informacionais no ensino acadêmico, o manual Handbook for information Literacy Teaching ${ }^{17} \mathrm{da}$ Universidade de Cardiff, traduzido e adaptado para o espanhol pela CRUE-TIC e REBIUN em 2012, podendo o mesmo ser remodelado para atender aos diferentes contextos locais.

\footnotetext{
16 A partir do conhecimento dos autores podem-se citar cursos e oficinas oferecidos pelo Laboratório de Tecnologia da Informação Documentária do Instituto de Ciências Humanas e da Informação; cursos ofertados pela Pró-Reitoria de Assuntos Estudantis e o projeto Inclusão digital através do Laboratório de Fontes de Informações Digitais do Sistema de Bibliotecas da FURG.

17 O manual se encontra no blog Alfared. Disponível em: <http://www.alfared.org/blog/bibliotecasuniversitarias/1414>. Acesso em: 26 maio 2014
} 


\section{REFERÊNCIAS}

APPOLINÁRIO, F. Metodologia da ciência: filosofia e prática da pesquisa. São Paulo: Cengage Learning, 2011.

ASSOCIATION OF COLLEGE AND RESEARCH LIBRARIES. Normas sobre aptitudes para el acceso y uso de la información em la Educación Superior. Tradução de Cristóbal Pasadas Ureña et al. 2000. Disponível em: <http://dialnet.unirioja.es/descarga/articulo/ 113346.pdf>. Acesso em:26 maio 2014.

BANDEIRA, D. P. Trajetórias de estudantes universitários de meios populares em busca de letramento digital. 2009. 272 p. Tese (Doutorado em Educação) - Programa de PósGraduação em Educação Conhecimento e Inclusão Social, Universidade Federal de Minas Gerais, Belo Horizonte, 2009. Disponível em: < http://www.bibliotecadigital.ufmg.br/ dspace/bitstream/1843/FAEC-83VSS5/1/trajetorias_em_pdf.pdf>. Acesso em: 26 maio 2014.

BRUCE, C. S. Las siete caras de la alfabetización en información en la ensañanza superior. Anales de Documentacion, n.6, p. 289-294, 2003. Trabalho original de 1997. Disponível em: <http://revistas.um.es/index.php/analesdoc/article/viewFile/3761/3661>. Acesso em:26 maio 2014.

CAMPELLO, B. S. Letramento informacional: função educativa do bibliotecário na escola. Belo Horizonte: Autêntica, 2009. (Biblioteca escolar).

CAVALCANTE, L. E. Políticas de formação para a competência informacional: o papel das universidades. R. Bras. de Biblioteconomia e Doc., v. 2, n. 2, p. 47-62, 2006. Disponível em: <http://www.febab.org.br/rbbd/index.php/rbbd/article/viewFile/17/5>. Acesso em:26 maio 2014.

COSTA, R. E. S. da. A competência em informação no ensino superior tecnológico: um estudo sobre os discentes e docentes do curso de análise e desenvolvimento de sistemas da união educacional de Brasília (UNEB). 196 f. Dissertação (Mestrado em Ciência da Informação) - Faculdade de Ciência da Informação, Universidade de Brasília, Brasília. 2011. Disponível em:<http://hdl.handle.net/10482/10991>. Acesso em:26 maio 2014.

CRUE-TIC; REBIUN (Comisión mixta). Competencias informáticas e informacionales en los estudios de grado. Ed. rev. e ampl. [Madrid: CRUE], 2012. Disponível em: < http://ci2.es/sites/default/files/documentacion/ci2_estudios_grado.pdf >. Acesso em: 26 maio 2014.

DANUELLO, J. C.; GONÇALVES, M. C. F. In(ex)clusão social: uma visão do profissional da informação sobre as diversas dificuldades de acesso informacional. R. EDICIC, v.1, n.3, p.70-82, jul./set. 2011. Disponível em: <http://www.edicic.org/revista/index.php? 
journal=RevistaEDICIC \&page $=$ article $\&$ op $=$ view $\&$ path $\% 5 \mathrm{~B} \% 5 \mathrm{D}=52>$. Acesso em: 26 maio 2014.

GASQUE, K. C. G. D. Letramento informacional: pesquisa, reflexão e aprendizagem. Brasília: Faculdade de Ciência da Informação/Universidade de Brasília, 2012. E-book. Disponível em: <

http://leunb.bce.unb.br/bitstream/handle/123456789/22/Letramento_Informacional.pdf?seque nce $=3>$. Acesso em:26 maio 2014 .

GRUPO TELEFÔNICA NO BRASIL. A sociedade da informação no Brasil: presente e perspectivas. [São Paulo]: Telefônica, 2002.

HATSCHBACH, M. H. de L. Information literacy: aspectos conceituais e iniciativas em ambiente digital para o estudante de nível superior. 2002. Dissertação (Mestrado em Ciência da Informação) - Escola de Comunicação, Universidade Federal do Rio de Janeiro MCT/IBICT, Rio de Janeiro, 2002. Disponível em: $<$ http://tede-dep.ibict.br/handle/tde/49 >. Acesso em: 26 maio 2014.

MASETTO, M. T. Inovação na aula universitária: espaço de pesquisa, construção de conhecimento interdisciplinar, espaço de aprendizagem e tecnologias de comunicação. Perspectiva, Florianópolis, v. 29, n. 2, p. 597-620, jul./dez. 2011. Disponível em: < https://periodicos.ufsc.br/index.php/perspectiva/article/view/2175795X.2011v29n2p597/22219 >. Acesso em:26 maio 2014.

MINAYO, M. C. de S. Pesquisa social: teoria, método e criatividade. 29. ed. Petrópolis, RJ: Vozes, 2010.

NERI, M. C. (Coord.). Mapa da inclusão digital. Rio de Janeiro: FGV, CPS, 2012. Disponível em: < http://www.cps.fgv.br/cps/bd/mid2012/MID_texto_principal.pdf >. Acesso em: 26 maio 2014.

NOVAES, D. Reflexões linguísticas para a organização hierárquica de conceitos em tesauros. In: DUQUE, C. G. (Org.). Ciência da informação estudos e práticas. Brasília: Centro Editorial, 2011. p. 97-152.

OLIVEIRA, G. P. de. Fluência tecnológica, comportamento e complexidades: um laboratório de informática, o tempo, as pessoas e outras coisas. Ensaio: aval. pol. públ. Educ., Rio de Janeiro vol.13, n. 48, p. 307-332, jul./set. 2005. Disponível em: < http://www.scielo.br/pdf/ensaio/v13n48/27552.pdf>. Acesso em:26 maio 2014.

PAVÃO, C. M. G. Comportamento de busca e recuperação da informação em serviços de descoberta em rede no contexto acadêmico. 2014. Tese (Doutorado em Comunicação e 
Informação) - Programa de Pós-graduação em Comunicação e Informação da Universidade Federal do Rio Grande do Sul, Porto Alegre, 2014.

SILVA, A. B. M. daet al. Espaço Europeu de Ensino Superior e a literacia informacional: conceitos e objectivos de um projecto de pesquisa aplicada em Ciência da Informação. Páginas a \& b: arquivos \& bibliotecas, série 2, n. 1, p. 103-123, 2008. Disponível em: < http://hdl.handle.net/10216/26362 >. Acesso em:26 maio 2014.

TAKAHASHI, T. (Org.). Sociedade da informação no Brasil: Livro Verde. Brasília, Ministério de Ciência e Tecnologia (MCT), 2000. Disponível em: <http://livroaberto.ibict.br/handle/1/434>. Acesso em: 26 maio 2014.

WAISELFISZ, J. J. Lápis, borracha e teclado: tecnologia da informação na educação Brasil e América Latina. Brasília: Instituto Sangari, 2007.

Como citar este documento:

GODINHO, Natalia Bermudez; GONÇALVES, Renata Braz; ALMEIDA, Alex Serrano de. Competências digitais e informacionais no ensino superior: um estudo com acadêmicos na Universidade Federal do Rio Grande - FURG. Revista Digital de Biblioteconomia e Ciência da Informação, Campinas, SP, v. 13, n. 2, p. 437-454, maio/ago. 2015. ISSN 1678765X. Disponível em: <http://periodicos.bc.unicamp.br/ojs/index.php/ rdbci/article/view/8635591>. Acesso em: 31 maio 2015. 
APÊNDICE A - Questionário (parcial)

\section{COMPETÊNCIA EM INFORMAÇÃO NO ENSINO SUPERIOR EM ESTUDANTES DO ICHI}

Prezado(a) acadêmico(a),

Este questionário faz parte de uma pesquisa de Iniciação Científica da Universidade Federal do Rio Grande FURG. Ele objetiva investigar as habilidades em lidar com a informação e os resultados visarão orientar futuras estratégias de ensino-aprendizagem. Este estudo necessita de sua ajuda no fornecimento dos dados abaixo, sendo que essa ajuda é totalmente voluntária e não implica em sua avaliação nas disciplinas cursadas, além de preservar o anonimato dos respondentes.

1. Qual a sua faixa etária?
a ( ) 15 a 20 anos
d ( ) 41 a 50 anos
b ( ) 21 a 30 anos
e ( ) 51 a 60 anos
c( ) 31 a 40 anos
$f($ ) acima de 61

\section{Qual o seu curso?}
a ( ) Arqueologia (Bach.)
b ( ) Arquivologia (Bach.)
c ( ) Biblioteconomia (Bach.)
d ( ) Geografia (Bach.)
e ( ) Geografia (Licenc.)
f ( ) História (Bach.)
g ( ) História (Licenc.)
h ( ) Psicologia (Bach.)

3. Qual o ano ou semestre cursado?

4. Esta é a primeira vez que você faz um curso de graduação?

a ( ) sim

b ( ) já cursei outra graduação, mas não dei continuidade no curso. Quanto tempo cursou?

c ( ) sou formado em outro curso.

5. Você dispõe de computador próprio?

$$
\text { d ( ) Sim b ( ) Não }
$$

6. Você julga que o bom desempenho no uso do computador (Ex.: editar e formatar textos, tabular dados numa planilha, digitar...) pode influenciar a realização de pesquisas acadêmicas? Comente sua resposta.

7. Como julga o seu desempenho frente ao uso do computador para realizar pesquisas acadêmicas? (Ex.: editar e formatar textos, tabular dados numa planilha, digitar...)

a ( ) Péssimo b ( ) Ruim c ( ) Razoável

d ( ) Bom e ( ) Excelente

8. Como julga o acesso à internet que você dispõe para realizar trabalhos acadêmicos? (quanto à velocidade, custos, local...)

a ( ) Péssimo b ( ) Ruim c ( ) Razoável

d ( ) Bom e ( ) Excelente

$f($ ) Não tenho acesso a internet 
9. Você julga que o bom desempenho no uso da internet pode influenciar na realização de pesquisas acadêmicas? Comente sua resposta.

a ( ) Sim b( ) Não

10. Como julga o seu desempenho frente ao uso da internet para realizar pesquisas acadêmicas? (Ex.: busca em catálogos on-line, bases de dados, compartilhamento de informações...)

a ( ) Péssimo b( ) Ruim c( ) Razoável

d ( ) Bom e ( ) Excelente

11. Você já se sentiu excluído por não saber utilizar o computador ou a internet, ou por não ter acesso a esses recursos? Comente sua resposta.

a ( ) Sim b( ) Não

12. Você tem dificuldade para usar computador ou internet voltados ao âmbito acadêmico? (Marque com um $x$ em quais recursos tem dificuldade)

\begin{tabular}{|c|c|c|c|c|}
\hline \multicolumn{2}{|r|}{ Recursos tecnológicos } & \multirow[t]{2}{*}{$\begin{array}{l}\text { Nenhuma } \\
\text { dificuldade }\end{array}$} & \multirow[t]{2}{*}{$\begin{array}{l}\text { Alguma } \\
\text { dificuldade }\end{array}$} & \multirow[t]{2}{*}{$\begin{array}{l}\text { Muita } \\
\text { dificuldade/ } \\
\text { não conhece }\end{array}$} \\
\hline a. & programa de aplicativos (Excel, PowerPoint ou similares,...) & & & \\
\hline b. & grupos, listas de discussões, fóruns (participar,...) & & & \\
\hline c. & redes sociais (Twitter, Facebook, Linkedin...) & & & \\
\hline d. & e-mail (encaminhar, anexar arquivos,...) & & & \\
\hline e. & bases de dados (portal de Periódicos da Capes, Scielo,...) & & & \\
\hline f. & $\begin{array}{l}\text { catálogos on-line de bibliotecas (Argo, Biblioteca } \\
\text { Nacional,...) }\end{array}$ & & & \\
\hline g. & $\begin{array}{l}\text { instalação de softwares, aplicativos, ferramentas, } \\
\text { navegadores,... }\end{array}$ & & & \\
\hline h. & $\begin{array}{l}\text { ferramentas Web } 2.0 \text { (Delicious, GoogleDocs, Google } \\
\text { Reader, RSS,...) }\end{array}$ & & & \\
\hline i. & gestores de referências (EndNote, Zotero...) & & & \\
\hline j. & criação de blogs, páginas na internet & & & \\
\hline k. & Outra. Qual? & & & \\
\hline
\end{tabular}

13. Você já pensou em desistir do curso devido a dificuldades no uso ou acesso ao computador ou internet? Comente sua resposta.
a $($ ) Sim
b （） Não 